\title{
ECOLOGY ENVIRONMENT RESEARCH ABOUT CARBON EMISSION EFFICIENCY IN CHINA BASED ON A NOVEL SUPER EPSILON-BASED MEASURES (SEBM) MODEL
}

\author{
SONG, A. ${ }^{1}-$ YANG, $X .^{2}-$ ZHANG, $X .^{3}-$ WANG, ${ }^{4}{ }^{4}-$ HUANG, W. ${ }^{1 *}$ \\ ${ }^{1}$ School of Management, Huazhong University of Science and Technology \\ Wuhan 430074, China \\ ${ }^{2}$ School of Management and Economics, North China University of Water Resources and \\ Electric Power, Zhengzhou 450045, China \\ ${ }^{3}$ School of Business, ZhengZhou Vocational College of Finance and Taxation \\ Zhengzhou 450048, China \\ ${ }^{4}$ School of Economics and Trade, Zhengzhou Institute of Technology \\ Zhengzhou 450044, China \\ *Corresponding author \\ e-mail: huangwl@mail.hust.edu.cn \\ (Received $18^{\text {th }}$ Sep 2018; accepted $26^{\text {th }}$ Nov 2018)
}

\begin{abstract}
With China's rapid economic development, the carbon emission has become a serious issue and the evaluation of carbon emission efficiency has drawn the attention of academia. Although the Data Envelopment Analysis (DEA) method is widely used in determining carbon emission efficiency, there are many limitations in the traditional DEA mathematical models including the original elements information loss due to the change of the proportion of the elements, too narrow efficiency boundaries, and the existence of undesirable outputs. As a result, a novel super epsilon-based measures (SEBM) carbon emission efficiency evaluation model is expected to overcome the limitations in the traditional carbon emission efficiency determination models, based on which the carbon emission efficiency of China is analyzed from time and spatial dimensions respectively. Finally, contrastive empirical analysis results of SEBM model and other classical DEA models indicate that the former has remarkable superiority over the other models. Based on the experimental results, it is found that China's carbon emission efficiency is inversely proportional to the level of economic development, and carbon emission efficiency values in China have generally increased, which highlights the significance of energy-saving emission reduction policies.
\end{abstract}

Keywords: data envelopment analysis (DEA), carbon emission efficiency, super epsilon-based measures (SEBM) model, empirical analysis (EA), model efficiency evaluation

\section{Introduction}

The competition between traditional energy and new energy has been intensifying. Traditional energy does not have the clean and pollution-free features of hydropower, solar energy, wind energy and other new energies (Wang et al., 2016). By contrast, traditional energies such as oil, coal and natural gas still occupy the principal position in global energy (Xu et al., 2014). A major concern of traditional energy sources is that carbon emissions are considered. Since energy conservation and emission reduction regulations were proposed in 2006, carbon emission reduction and carbon emission efficiency improvement are used as metrics by all sectors of society (Roar Adland et al., 2017). The emergence of electric vehicles is caused by industrial circles (Yun et al., 2017). Research on carbon emission efficiency is also on the rise (Henson et al., 2015). China, as the world's largest developing 
country, has continuously and rapidly expanded its economy since the late 1980s, maintaining an annual growth rate of more than 9\% for over three decades (Wang et al., 2015). China's extensive economic growth is condemned to have high-energy consumption, high carbon emissions and other issues (Wang et al., 2013). Taking carbon emission efficiency as the entry point, this study takes the information from all of the regions in China as data support, conducts innovation research expansion on the most popular carbon emission efficiency model from the academic literature, and comparatively analyses on the carbon emission efficiency model in 29 provinces and cities in China (Liu et al., 2014).

Our study aims to design an SEBM model to evaluate carbon emission efficiency, which can solve the problems which other models cannot solve. There are two streams of relevant literature surrounding this research: the focus issues of carbon emission efficiency in the academic literature and the data envelopment analysis (DEA)-based carbon emission efficiency evaluation models.

Early researchers primarily used the ratio of total carbon emissions together with a select factor as the evaluation index of carbon efficiency, namely, single element carbon efficiency. For example, the carbon emissions efficiency, known as carbon productivity, was defined as the ratio of GDP and the carbon emissions during a select period (Kaya and Yokobori, 1993). Later, carbon index (carbon emissions perunit energy consumption), energy intensity (energy consumption per unit of GDP) and carbon emissions intensity index $\left(\mathrm{CO}_{2}\right.$ emissions per unit of GDP) were used as the evaluation index to measure carbon efficiency (Mielnik and Goldemberg, 1999; Ang, 1999; Sun, 2005). In addition, new evaluation indices such as industrialization cumulative per capita emissions, and carbon emissions by per capita per unit GDP were found to better reflect scientific, fair and reasonable principles, so they became more reasonable indices for the measurement of carbon efficiency evaluation (Zhang et al., 2008). Single factor index evaluation carbon efficiency is easy to understand and operate, but there are different opinions about its usefulness, because of the diversity of the measurement index (Zhou et al., 2010). Therefore, many researchers have relied on total factor efficiency to determine carbon emissions. For instance, the carbon emissions efficiency should be integrated into the three contexts of energy consumption, economic development and carbon emissions; so that the evaluation results are comprehensive and rational (Ramanathan, 2002). And slack variables were used to measure the comprehensive performance of carbon emissions of 30 OECD countries during the period of 1998-2002 (Zhou et al., 2006). Furthermore, bidirectional causality between economic growth and energy use and between energy use and carbon emissions (Wang et al., 2016).

In recent years, domestic and foreign researchers have generally used DEA to examine the efficiency of carbon emissions within the framework of the total factor. Ramanathan (2005, 2006) integrated the four indices of $\mathrm{CO}_{2}$ emissions using DEA, and obtained the $\mathrm{CO}_{2}$ emissions efficiency of 17 countries in the Middle East and North Africa. Marklund and Samakovlis (2007) estimated the cost of carbon emissions reduction of the European countries by building a distance-direction function based on the DEA. Zhou et al. (2010) measured the carbon emissions efficiency of 18 countries with the highest global $\mathrm{CO}_{2}$ emissions using MCPI, and constructed a correlation analysis of the influencing factors of carbon emissions efficiency. Wang and Zhou (2012) used the DEA method to measure the carbon emission efficiency of each province in China from 2001 to 2007 and concluded that China's carbon emission efficiency varied. Zhou and Nie used the slack-based measure 
(SBM) to quantify the inter-provincial industrial carbon emission efficiency of 30 provinces in China and analyse the similarities and differences (Grinsven et al., 2016).

From the perspective of a carbon emission efficiency model, the academic community relies on DEA to analyze carbon emission efficiency (Niu et al., 2016). The model development process first adopted the CCR-DEA model and then the BCC-DEA model, which examines carbon emission efficiency in constant returns to scale (CRS) and variable returns to scale (VRS) (Cranmer, 2016). After the DEA model developed the SBM and other models to consider the non-expected output, researchers have mostly used the SBMDEA model or other relevant models supported by it. For example, carbon emission efficiency is calculated using the SBM model; the stochastic frontier analysis or redundancy analysis is used to revise the efficiency value, and the three-stage DEA model of SBM efficiency, Tobit regression or Malmquist index is used to analyze the carbon emission efficiency (Kim, 2016). Alternatively, the SBM from an operational research perspective and statistical regression are combined to examine carbon emission efficiency (Baleentis et al., 2016), but research on the applicability of the model is not comprehensive. Some scholars have proposed the super-efficiency-DEA (SE-DEA) to enlarge the efficiency boundary of carbon emission and effectively eliminate the limitation of the efficiency value boundary of the original DEA model (Szczepańska and Wiśniewska, 2012). Some scholars have partially supplemented the DEA model from the radial direction and non-radial direction angles of the directional distance function. In 2016, a series of significant progress in theory was made: Tone summarised the shortcomings of CRS and SBM models and proposed the epsilon-based measure model (EBM), which solves the problem of the proportional change in factors and the original ratio information of loss efficiency frontier (Andrie and Ursu, 2016). However, the efficiency boundary remained restricted, and the model was still insufficient. In consideration of the advantages and disadvantages of the CCR-BCC-SBM-EBM-SE model, this study proposes the SEBM model (Bretschger and Valente, 2016), which can effectively expand the efficiency of the boundary and solve the factor changes in the same proportion, the original ratio information of factors in the leading edge of loss efficiency and other issues (Shao and Wang, 2016). The current study also provides further theoretical and data support for other scholars in studying carbon emission efficiency.

The article structure is presented as follows: in Section 2, the classical mathematical models in data envelopment analysis (DEA) are presented, including the Charnes, Cooper and Rhodes (CCR) model, the Banker, Charnes and Cooper (BCC) model, the superefficiency-data envelopment analysis (SE-DEA) model and the epsilon-based measure (EBM) model. Then, a novel super epsilon-based measures (SEBM) model is proposed further in Section 3. Section 4 discusses and analyses the differences in carbon emission efficiency in 29 regions in China from 2004 to 2014, where the characteristics of classical DEA models of CCR, EBM, SE models and the proposed SEBM model are comparatively analyzed from the time and spatial dimension. Section 5 concludes the paper.

\section{Materials and methods: theoretical model establishment}

The DEA method is widely used in determining carbon emission efficiency (Xian and Huang, 2016). This section discusses the CCR-DEA, BCC-DEA, SE-DEA, EBMDEA and SEBM-DEA models from a theoretical perspective. From the variable perspective, the DEA model has an input-oriented angle and an output-oriented angle but no guidance angle (Dzonzi-Undi and Li, 2016; Obeng et al., 2016; Vaidya and 
Campbell, 2016). This study only provides the theoretical formula of the three angle models of the SEBM model.

Suppose we have a set of independent homogeneous decision-making units denoted by $D M U_{j}(j=1,2, . n)$. Each observation $D M U_{j}(j=1,2, . . n)$ uses $m$ inputs $x_{i j}(i=1,2, . . m)$ to produce $s$ outputs $y_{r j}(r=1,2 \ldots s)$. DMU $U_{o}$ represents one of the $n$ DMUs under evaluation, and $\mathrm{x}_{i o}$ and $y_{r o}$ are the $\mathrm{i}^{\text {th }}$ input and $\mathrm{r}^{\text {th }}$ output for $D M U_{o}$, respectively.

\section{CCR model}

The technical efficiency of the $\mathrm{O}^{\text {th }} \mathrm{DMU}$ can be calculated by the input-oriented CCR (Charanes et al., 1978) model (Eq.1):

$$
\begin{array}{cl}
\text { Min } \theta_{o} & \\
\text { subject to } & \sum_{j=1}^{n} x_{i j} \lambda_{j} \leq \theta_{o} x_{i o}, i=1,2, \ldots, m, \\
& \sum_{j=1}^{n} y_{r j} \lambda_{j} \geq y_{r o}, r=1,2, \ldots, s, \\
& \lambda_{j} \geq 0, j=1,2, \ldots, n .
\end{array}
$$

where $v_{i}$ and $u_{r}$ are the weights assigned to input $\mathrm{i}(i=1,2, . . m)$ and output $\mathrm{r}(r=1,2, . . s)$, respectively, and $\lambda$ is the weight multiplier of each DMU. In the above formula, the optimal solution $\theta_{o}^{*}$ represents the efficiency value $\theta_{o}^{*} \in(0,1]$.

\section{BCC model}

The BCC model assumes that the production process belongs to a fixed-scale gain. That is, when the input amount increases in geometric proportion, the output also increases in geometric proportion (Sarkar, 2013). However, the actual production process may also belong to the state of increasing returns to scale or decreasing returns to scale. To analyze the changes in returns to scale of the DMUs, Banker et al. (1984) proposed the BCC model (Eq. 2):

$$
\begin{array}{ll}
\text { Min } \theta_{o} & \\
\text { subject to } & \sum_{j=1}^{n} x_{i j} \lambda_{j} \leq \theta_{o} x_{i o}, i=1,2, \ldots, m, \\
& \sum_{j=1}^{n} y_{r j} \lambda_{j} \geq y_{r o}, r=1,2, \ldots, s, \\
& \sum_{j=1}^{n} \lambda_{j}=1, \\
& \lambda_{j} \geq 0, j=1,2, \ldots, n .
\end{array}
$$

Compared with the CCR model, the constraint $\sum_{i=1}^{n} \lambda j=1$ is added to the BCC model, so that the production scale of the projection point is at the same level as the scale of production being evaluated. 


\section{SE-DEA model}

If the effective DMUs are too affected by the effect of data on the CCR model, no comparison exists. Andersen and Petersen (1993) removed the assessed DMUs from the efficient boundary and took the remaining DMUs as basis to form a new efficiency boundary and calculate the distance from the removed DMU to the new efficient boundary. Thus, all of the DMUs achieved complete sequencing, that is, the superefficiency model. The SE-DEA model (Eq. 3) based on the CCR model is expressed as follows:

$$
\begin{aligned}
& \operatorname{Min} \theta_{o} \\
& \text { subject to } \sum_{\substack{j=1 \\
j \neq o}}^{n} x_{i j} \lambda_{j} \leq \theta_{o} x_{i o}, i=1,2, \ldots, m, \\
& \sum_{\substack{j=1 \\
j \neq o}}^{n} y_{r j} \lambda_{j} \geq y_{r o}, r=1,2, \ldots, s, \\
& \sum_{\substack{j=1 \\
j \neq 0}}^{n} \lambda_{j}=1 \\
& \lambda_{j} \geq 0, j \neq o .
\end{aligned}
$$

Banker and Chang (2006) demonstrated that the super-efficiency model is highly susceptible to outliers, and thus, the model could detect the existence of outliers in the dataset. In a number of datasets of effective DMUs, SE-DEA effectively was shown to amplify the efficiency boundary, and many practical problems were analyzed effectively because of the limitation of the previous efficiency boundary. The SE-DEA reveals the potential for these practical applications.

\section{EBM model}

In 2010, Tone argued that the same rate reduction of input factor in traditional DEA (CCR) models violates physical truth and that the SBM model has the original ratio information of factors aside from loss efficiency. He proposed the EBM model which overcame the above shortcomings. The model's theoretical formulas are expressed as follows (Eq. 4):

$$
\begin{array}{ll}
\gamma^{*}=\operatorname{Min} & \theta_{o}-\varepsilon^{-} \sum_{i=1}^{m} \frac{w_{i}^{-} s_{i}^{-}}{x_{o}} \\
\text { subject to } & \sum_{j=1}^{n} x_{i j} \lambda_{j}+s_{i}^{-}=\theta_{o} x_{i o}, i=1, \ldots, m, \\
& \sum_{j=1}^{n} y_{r j} \lambda_{j} \geq y_{r o}, \quad r=1, \ldots, s, \\
& \lambda_{j}, s_{i}^{-} \geq 0, \quad \forall i, j, r .
\end{array}
$$

This formulation indicates that $\gamma^{*}$ is obtained as the optimal internally dividing value between the radial $\theta_{o}$ and the non-radial term $\varepsilon \sum_{i=1}^{m} \frac{w_{i}{ }^{-} s_{i}{ }^{-}}{x_{o}}$, where $s_{i}{ }^{-}$is the amount 
of slack in the $\mathrm{i}^{\text {th }}$ input, and $w_{i}{ }^{-}$is the $\mathrm{i}^{\text {th }}$ input weight and satisfies $\sum_{i=1}^{m} w_{i}^{-}=1\left(w_{i}^{-} \geq 0, \forall i\right)$.

$\varepsilon^{-}$is a key parameter in the range of $[0,1]$, and it indicates the importance of the nonradial part in the calculation of the efficiency value. If $\varepsilon^{-}=0$, the EBM model will be simplified as the input-oriented CCR model. If $\theta_{o}=\varepsilon^{-}=1$, the EBM model will be transformed into the SBM model. Before calculating the EBM efficiency scores, we should first estimate the value of the core parameters $\varepsilon^{-}$and $w_{i}{ }^{-}$. We determine $\varepsilon^{-}$ and $w_{i}^{-}$using Pearson's correlation coefficient (Tavana et al., 2013; Tone and Tsutsui, 2010).

\section{Results: the proposed SEBM model}

The theoretical analysis and research on the CCR, BCC, SEDEA and EBM models are presented. To overcome these three problems, first, the input efficiency should have the same reduction rate. Second, if too many effective units exist, the actual problems will not be effectively analyzed. Third, the original ratio information of the factor of the leading edge of loss efficiency should be obtained. In this study, the SEBM model is presented, and the theoretical formula of the SEBM model is given in three aspects:

Input-orientation (Eq. 5):

$$
\begin{array}{cc}
\gamma^{*}=\operatorname{Min} & \theta_{o}-\varepsilon^{-} \sum_{i=1}^{m} \frac{w_{i}^{-} s_{i}^{-}}{x_{o}} \\
\text { subject to } & \sum_{\substack{j=1 \\
j \neq o}}^{n} x_{i j} \lambda_{j}+s_{i}^{-}=\theta_{o} x_{i o}, i=1, \ldots, m, \\
\sum_{\substack{j=1 \\
j \neq o}}^{n} y_{r j} \lambda_{j} \geq y_{r o}, \quad r=1, \ldots, s, \\
\sum_{\substack{j=1 \\
j \neq o}}^{n} \lambda_{j}=1, \\
\lambda_{j}, s_{i}^{-} \geq 0, \quad \forall i, j, r .
\end{array}
$$

Output-orientation (Eq. 6):

$$
\begin{aligned}
\gamma *=\operatorname{Min} & \frac{1}{\varphi_{\mathbf{0}}-\varepsilon^{+} \sum_{i=1}^{s} \frac{w_{i}^{+} s_{i}^{+}}{x_{o}}} \\
\text { subject to } & \sum_{\substack{j=1 \\
j \neq o}}^{n} x_{i j} \lambda_{j} \geq x_{i o}, i=1, \ldots, q, \\
& \sum_{\substack{j=1 \\
j \neq 0}}^{n} y_{r j} \lambda_{j}-s_{r}^{+}=\varphi_{\mathbf{0}} y_{r o}, \quad r=1, \ldots, s, \\
& \sum_{\substack{j=1 \\
j \neq o}}^{n} \lambda_{j}=1, \\
& \lambda_{j}, s_{r}^{+} \geq 0, \quad \forall i, j, r .
\end{aligned}
$$


In the above model, the reciprocal of $\gamma^{*}$ is obtained as the optimal internally dividing value between the radial $\varphi_{o}$ and the non-radial term $\varepsilon^{+} \sum_{i=1}^{m} \frac{w_{i}{ }^{-} s_{i}^{-}}{x_{o}}$, where $s_{i}{ }^{+}$is the amount of slack in the $\mathrm{i}^{\text {th }}$ output, and $w_{i}^{+}$is the $\mathrm{i}^{\text {th }}$ output weight and satisfies $\sum_{i=1}^{m} w_{i}^{+}=1\left(w_{i}^{+} \geq 0, \forall i\right) . \varepsilon^{+}$is a key parameter in the range of $[0,1]$. This indicates the importance of the non-radial part in the calculation of the efficiency value.

Non-orientation (Eq. 7):

$$
\begin{array}{cl}
\gamma^{*}=\operatorname{Min} \frac{\theta_{o}-\varepsilon^{-} \sum_{i=1}^{n} \frac{w_{i}^{-} s_{i}^{-}}{x_{o}}}{\varphi_{o}-\varepsilon^{+} \sum_{i=1}^{s} \frac{w_{i}^{+} s_{i}^{+}}{x_{o}}} \\
\text { subject to } & \sum_{\substack{j=1 \\
j \neq o}}^{n} x_{i j} \lambda_{j}+s_{i}^{-}=\theta_{o} x_{i o}, i=1, \ldots, m, \\
& \sum_{\substack{j=1 \\
j \neq o}}^{n} y_{r j} \lambda_{j}-s_{r}^{+}=\varphi_{o} y_{r o}, \quad r=1, \ldots, s, \\
& \sum_{\substack{j=1 \\
j \neq o}}^{n} \lambda_{j}=1, \\
\lambda_{j}, s_{i}^{-}, s_{r}^{+} \geq 0, \quad \forall i, j, r .
\end{array}
$$

The SEBM model effectively solves several problems of the DEA model. Regarding applicability, the expansion of an efficient boundary can be applied in more datasets. SEBM can be applied in an actual situation to remove the ratio change restrictions of the input elements. System errors can be avoided without loss of the original data information.

\section{Discussion: empirical analysis}

\section{Data description}

In this study, Chinese human capital stock and total energy consumption in 2017 are taken as input factors. Output indicators include GDP and carbon emissions, which are desirable outputs in the CCR/BCC/SE model and are undesirable outputs in the EBM and SEBM models. The input and output data are obtained from the 'China Statistical Yearbook' and 'China Energy Statistical Yearbook'. The basic descriptive statistics of the 29 regions in China are shown in Table 1.

\section{Spatial dimension analysis}

In this section, we first calculate the optimal value of each DMU using CCR, BCC, SE-DEA, EBM and SEBM models under CRS and VRS. The results are shown in Tables 2 and 3, respectively. We then analyze the differences in carbon emission efficiency in 29 regions of China from the spatial dimension. According to the spatial distribution, the efficiency value in the west is the highest, followed by the middle, and the lowest in the east. This finding suggests that the technology and management level 
in the west is relatively high. To reflect clearly the regional variability of the four models results, we illustrate them in Figures 1 and 2.

Table 1. Descriptive statistics

\begin{tabular}{c|c|c|c|c|c}
\hline Statistics & Minimum (M) & Maximum (X) & Average value (E) & Standard error & $\begin{array}{c}\text { Standard } \\
\text { deviation }\end{array}$ \\
\hline $\begin{array}{c}\text { GDP } \\
\text { (billion yuan) }\end{array}$ & 113.52 & 16413.66 & 3196.5712 & 162.21195 & 2897.19812 \\
\hline $\begin{array}{c}\text { Labor force } \\
\text { (ten thousand } \\
\text { people) }\end{array}$ & 94.10 & 4500.05 & 1002.3773 & 41.45137 & 740.34507 \\
\hline $\begin{array}{c}\text { Capital stock } \\
\text { (ten thousand } \\
\text { yuan) }\end{array}$ & 178.68 & 48416.44 & 7317.7862 & 421.18654 & 7522.63220 \\
\hline $\begin{array}{c}\text { Total energy } \\
\text { consumption } \\
\text { (million tons of } \\
\text { standard coal) }\end{array}$ & 742.48 & 38899.25 & 11990.4673 & 437.90044 & 7821.15186 \\
\hline $\begin{array}{c}\text { Carbon emission } \\
\text { (ton) }\end{array}$ & 343.47 & 34923.51 & 9373.4433 & 381.42376 & 6812.44625 \\
\hline
\end{tabular}

Table 2. Carbon emission efficiency in China's provinces: constant returns to scale

\begin{tabular}{c|c|c|c|c|c|c|c|c|c}
\hline \multirow{4}{*}{ Central } & Regions & $\begin{array}{c}\text { CCR- } \\
\text { DEA }\end{array}$ & Ranking & $\begin{array}{c}\text { EBM- } \\
\text { DEA }\end{array}$ & Ranking & $\begin{array}{c}\text { SE- } \\
\text { DEA }\end{array}$ & Ranking & $\begin{array}{c}\text { SEBM- } \\
\text { DEA }\end{array}$ & Ranking \\
\hline & Henan & 0.482 & 14 & 0.577 & 21 & 0.482 & 14 & 0.577 & 21 \\
& Hubei & 0.425 & 18 & 0.609 & 17 & 0.425 & 18 & 0.609 & 17 \\
& Hunan & 0.545 & 11 & 0.785 & 8 & 0.545 & 11 & 0.785 & 8 \\
& Jiangxi & 0.257 & 28 & 0.457 & 29 & 0.257 & 28 & 0.457 & 29 \\
& Anhui & 0.399 & 20 & 0.547 & 23 & 0.399 & 20 & 0.547 & 23 \\
& Shanxi & 0.923 & 2 & 0.890 & 4 & 0.938 & 2 & 0.891 & 4 \\
& Jilin & 0.472 & 15 & 0.554 & 22 & 0.472 & 15 & 0.554 & 22 \\
& Heilong jiang & 0.505 & 13 & 0.644 & 11 & 0.505 & 13 & 0.644 & 11 \\
\hline \multirow{5}{*}{ Eastern } & Beijing & 0.206 & 29 & 0.651 & 10 & 0.206 & 29 & 0.651 & 10 \\
& Tianjin & 0.548 & 9 & 0.602 & 18 & 0.548 & 9 & 0.602 & 18 \\
& Hebei & 0.764 & 6 & 0.788 & 7 & 0.764 & 6 & 0.788 & 7 \\
& Liaoning & 0.557 & 8 & 0.628 & 15 & 0.557 & 8 & 0.628 & 15 \\
& Shanghai & 0.329 & 23 & 0.497 & 27 & 0.329 & 23 & 0.497 & 27 \\
& Jiangsu & 0.311 & 25 & 0.458 & 28 & 0.311 & 25 & 0.458 & 28 \\
& Zhejiang & 0.282 & 27 & 0.520 & 25 & 0.282 & 27 & 0.520 & 25 \\
& Fujian & 0.373 & 22 & 0.634 & 12 & 0.373 & 22 & 0.634 & 12 \\
& Shandong & 0.524 & 12 & 0.590 & 19 & 0.524 & 12 & 0.590 & 19 \\
& Guangdong & 0.318 & 24 & 0.589 & 20 & 0.318 & 24 & 0.589 & 20 \\
& Hainan & 0.308 & 26 & 0.522 & 24 & 0.308 & 26 & 0.522 & 24 \\
\hline \multirow{7}{*}{ regions }
\end{tabular}




\begin{tabular}{c|c|c|c|c|c|c|c|c|c}
\hline & Inner Mongolia & 0.907 & 3 & 0.889 & 5 & 0.919 & 3 & 0.890 & 5 \\
& Guangxi & 0.396 & 21 & 0.628 & 14 & 0.396 & 21 & 0.628 & 14 \\
& Sichuan & 0.857 & 4 & 0.989 & 1 & 0.868 & 4 & 0.991 & 1 \\
Western & Guizhou & 0.452 & 16 & 0.744 & 9 & 0.452 & 16 & 0.744 & 9 \\
regions & Yunnan & 0.745 & 7 & 0.826 & 6 & 0.745 & 7 & 0.826 & 6 \\
& Shaanxi & 0.442 & 17 & 0.632 & 13 & 0.442 & 17 & 0.632 & 13 \\
& Gansu & 0.410 & 19 & 0.498 & 26 & 0.410 & 19 & 0.498 & 26 \\
& Qinghai & 0.547 & 10 & 0.610 & 16 & 0.547 & 10 & 0.610 & 16 \\
& Ningxia & 0.842 & 5 & 0.983 & 2 & 0.842 & 5 & 0.985 & 2 \\
& Xinjiang & 0.978 & 1 & 0.964 & 3 & 0.996 & 1 & 0.966 & 3 \\
\hline
\end{tabular}

Table 3. Carbon emission efficiency in China's provinces: variable returns to scale

\begin{tabular}{|c|c|c|c|c|c|c|c|c|c|}
\hline & Region & $\begin{array}{l}\text { BCC- } \\
\text { DEA }\end{array}$ & Ranking & $\begin{array}{l}\text { EBM- } \\
\text { DEA }\end{array}$ & Ranking & $\begin{array}{c}\text { SE- } \\
\text { DEA }\end{array}$ & Ranking & $\begin{array}{c}\text { SEBM- } \\
\text { DEA }\end{array}$ & Ranking \\
\hline \multirow{8}{*}{$\begin{array}{l}\text { Central } \\
\text { regions }\end{array}$} & Henan & 0.655 & 11 & 0.834 & 12 & 0.655 & 11 & 0.834 & 12 \\
\hline & Hubei & 0.480 & 21 & 0.785 & 14 & 0.480 & 21 & 0.785 & 14 \\
\hline & Hunan & 0.675 & 10 & 0.956 & 8 & 0.675 & 10 & 0.957 & 8 \\
\hline & Jiangxi & 0.278 & 28 & 0.512 & 29 & 0.278 & 28 & 0.512 & 29 \\
\hline & Anhui & 0.406 & 25 & 0.640 & 25 & 0.406 & 25 & 0.640 & 25 \\
\hline & Shanxi & 0.986 & 1 & 0.985 & 4 & 1.018 & 3 & 0.987 & 5 \\
\hline & Jilin & 0.481 & 20 & 0.660 & 23 & 0.481 & 20 & 0.660 & 23 \\
\hline & Heilong jiang & 0.515 & 18 & 0.767 & 16 & 0.515 & 18 & 0.767 & 16 \\
\hline \multirow{12}{*}{$\begin{array}{l}\text { Eastern } \\
\text { regions }\end{array}$} & Beijing & 0.234 & 29 & 0.686 & 21 & 0.234 & 29 & 0.686 & 21 \\
\hline & Tianjin & 0.553 & 16 & 0.665 & 22 & 0.553 & 16 & 0.665 & 22 \\
\hline & Hebei & 0.969 & 4 & 0.987 & 3 & 0.981 & 5 & 0.989 & 4 \\
\hline & Liaoning & 0.740 & 9 & 0.820 & 13 & 0.740 & 9 & 0.820 & 13 \\
\hline & Shanghai & 0.341 & 27 & 0.611 & 27 & 0.341 & 27 & 0.611 & 27 \\
\hline & Jiangsu & 0.489 & 19 & 0.764 & 17 & 0.489 & 19 & 0.764 & 17 \\
\hline & Zhejiang & 0.419 & 23 & 0.690 & 20 & 0.419 & 23 & 0.690 & 20 \\
\hline & Fujian & 0.381 & 26 & 0.723 & 19 & 0.381 & 26 & 0.723 & 19 \\
\hline & Shandong & 0.973 & 3 & 0.957 & 7 & 0.991 & 4 & 0.958 & 7 \\
\hline & Guangdong & 0.571 & 12 & 0.912 & 11 & 0.571 & 13 & 0.914 & 11 \\
\hline & Hainan & 0.565 & 14 & 0.619 & 26 & 0.591 & 12 & 0.624 & 26 \\
\hline & Region & $\begin{array}{l}\text { BCC- } \\
\text { DEA }\end{array}$ & Ranking & $\begin{array}{l}\text { EBM- } \\
\text { DEA }\end{array}$ & Ranking & $\begin{array}{l}\text { SE- } \\
\text { DEA }\end{array}$ & Ranking & \begin{tabular}{|c|} 
SEBM- \\
DEA
\end{tabular} & Ranking \\
\hline \multirow{10}{*}{$\begin{array}{l}\text { Western } \\
\text { regions }\end{array}$} & Inner Mongolia & 0.953 & 0 & 0.928 & 7 & 0.968 & 6 & 0.929 & 9 \\
\hline & Guangxi & 0.410 & 24 & 0.734 & 18 & 0.410 & 24 & 0.734 & 18 \\
\hline & Sichuan & 0.955 & 5 & 0.995 & 1 & 1.023 & 2 & 1.003 & 2 \\
\hline & Guizhou & 0.569 & 13 & 0.963 & 6 & 0.569 & 14 & 0.964 & 6 \\
\hline & Yunnan & 0.762 & 8 & 0.916 & 10 & 0.764 & 8 & 0.918 & 10 \\
\hline & Shaanxi & 0.517 & 17 & 0.781 & 15 & 0.517 & 17 & 0.781 & 15 \\
\hline & Gansu & 0.425 & 22 & 0.599 & 28 & 0.425 & 22 & 0.599 & 28 \\
\hline & Qinghai & 0.558 & 15 & 0.659 & 24 & 0.558 & 15 & 0.659 & 24 \\
\hline & Ningxia & 0.929 & 7 & 0.992 & 2 & 0.960 & 7 & 1.003 & 1 \\
\hline & Xinjiang & 0.984 & 2 & 0.983 & 5 & 1.030 & 1 & 0.989 & 3 \\
\hline
\end{tabular}




$$
-1118 \text { - }
$$

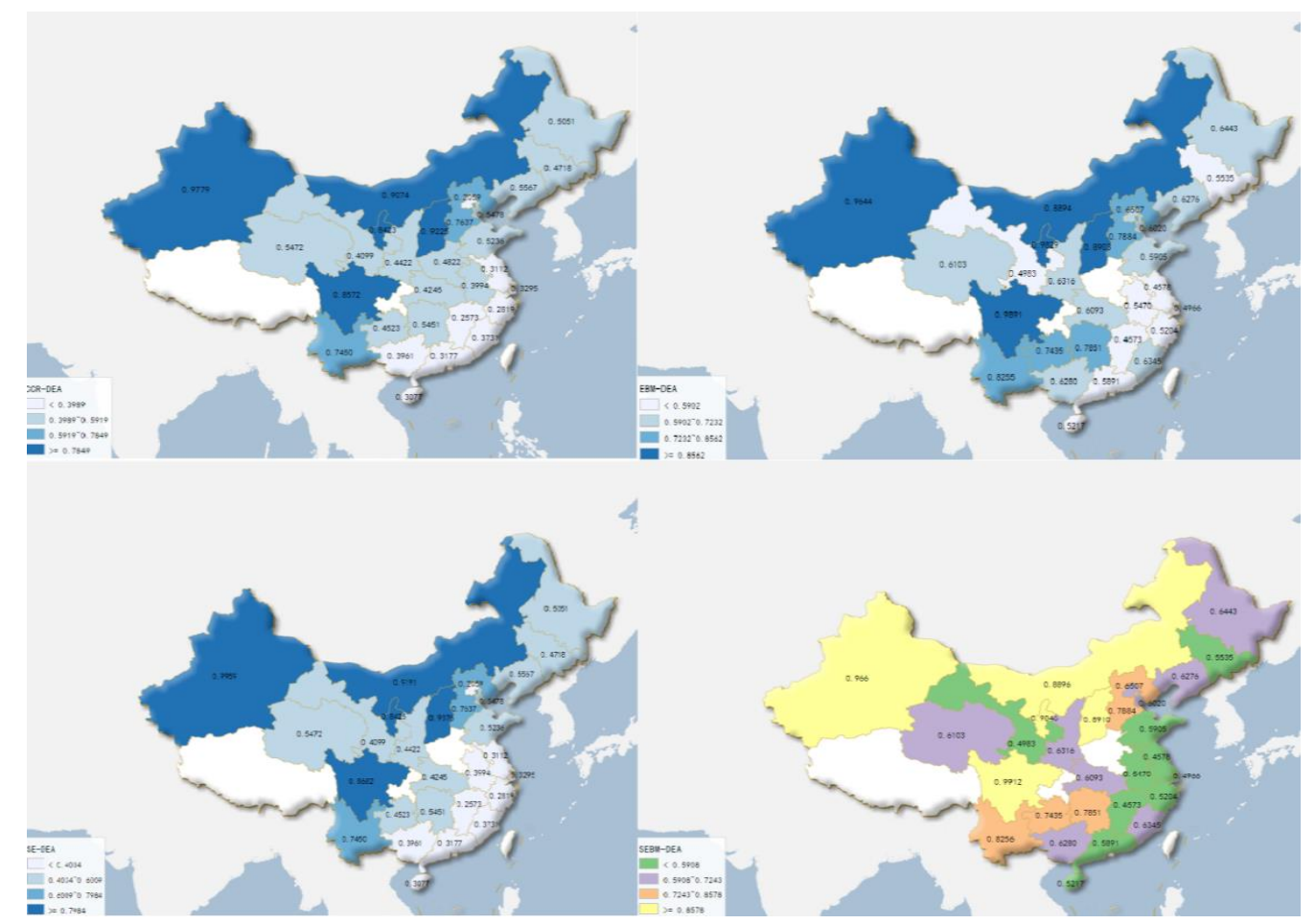

Figure 1. Spatial dimension analysis of carbon emissions efficiency in China from 2004 to 2014: constant returns to scale

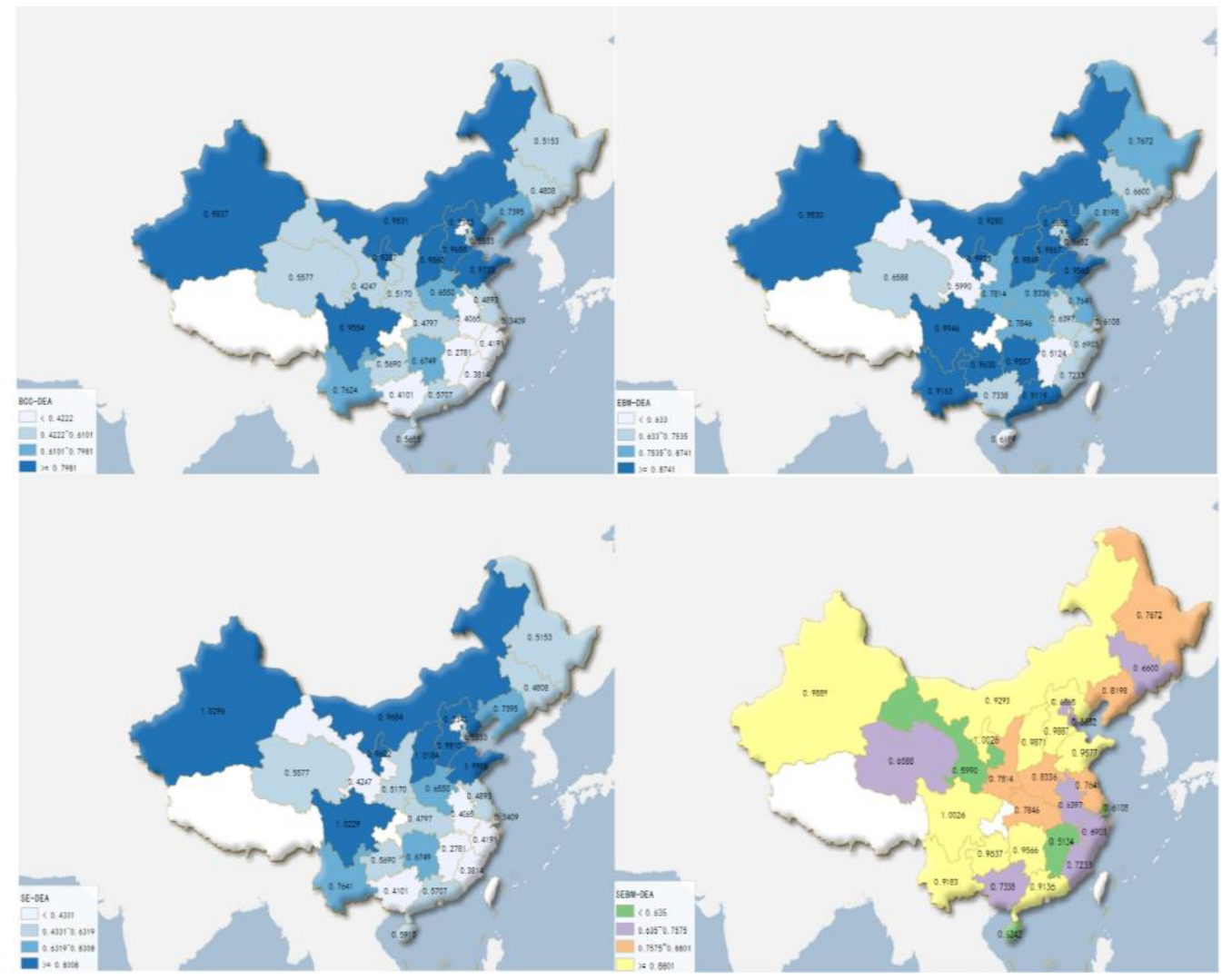

Figure 2. Spatial dimension analysis of carbon emissions efficiency in China from 2004 to 2014: variable return scale 


\section{CCR-DEA/BCC-DEA efficiency evaluation}

CCR is the most basic DEA model under the CRS angle. Technical efficiency is the production efficiency of the DMU under an optimal scale. However, the DMU is mostly provided with VRS, and thus the BCC model is more suitable in real situations.

As shown in Tables 2 and 3 and Figures 1 and 2, specific to the CCR model, the efficiency values in all provinces are below 1, and the DEA is not valid in all. The carbon emission efficiencies in Xinjiang, Shanxi and Inner Mongolia are above 0.9, which is relatively high. The efficiency values in Jiangxi, Beijing and Zhejiang are below 0.3 , which is relatively low. This finding indicates a huge difference in carbon emission efficiency among the different provinces and that the total carbon emission efficiency in China is relatively low. The carbon emission efficiency value in the western region is high, and the efficiency values in six of the ten provinces in the western region are greater than 0.5 . The carbon emission efficiency values in the eastern region are the lowest, and the efficiency values in seven of the eleven provinces are less than 0.4. The carbon emission efficiency values in the middle are ranked between those in the west and those in the east. The efficiency values in most of these provinces range from 0.4-0.55.

Specific to the BCC model, the efficiency values in all provinces are below 1 . The pure technical efficiency is not valid, but the whole efficiency values are higher than those of the CCR model. The efficiency values in seven provinces are above 0.9, and Shanxi, Xinjiang and Shandong are the top three in efficiency value. The efficiency values in Jiangxi, Beijing and Shanghai are the lowest at below 0.4. In summary, the efficiency values obtained from the BCC model with VRS are applicable in actual situations.

\section{EBM-DEA efficiency evaluation}

As the assumed condition of the radial CCR model is too strict, the identified efficiency values usually differ from the actual economy conditions. Therefore, the EBM model combined with radial and non-radial characteristics can effectively solve the problems existing in the CCR model measurement.

From the CRS angle, the comparison of efficiency values of the CCR model and the EBM model shows that the EBM efficiency value is higher than the CCR efficiency value. As shown in Tables 2 and 3 and Figures 1 and 2, Sichuan, Ningxia and Xinjiang are the top three in efficiency values obtained from the EBM model with the efficiency values above 0.9. Jiangxi, Jiangsu and Shanghai are at the bottom three. The ranks decrease compared with the CCR efficiency value. But the efficiency values, which are all above 0.45 , increase. This result shows that the EBM model can effectively solve conditions with extreme measurement values in the CCR model with the measurement result closer to the actual economy conditions.

From the VRS angle, BCC efficiency value and EBM efficiency value indicate that the EBM efficiency value is relatively high. Sichuan, Ningxia and Hebei are the top three in efficiency values gained from the EBM model. They all increased compared with BCC efficiency value ranking. Jiangxi, Gansu and Shanghai are the bottom three. Although Shanghai, Jiangxi and Gansu are ranked in a lower position than the BCC efficiency value ranking, all efficiency values approximately increase. 


\section{SE-DEA efficiency evaluation}

When the traditional DEA model measures and compares the efficiency value, there is a defect that multiple decision-making units of leading surface cannot be further compared and evaluated. However, the SE-DEA model can measure the valid DMUs of the DEA by transmitting the DMUs to the leading surface.

In the CRS angle, with respect to the basic CCR model, the average SE-DEA efficiency value in Shanxi, Inner Mongolia, Xinjiang and Sichuan in 2004-2014 decreases because the DEA in these four provinces is valid for some of the identified years. Therefore, the SE-DEA measures those years in which the leading line for production is reached. For example, as shown in Tables 2 and 3 and Figures 1 and 2, the DEA of Shanxi is valid in 2004, 2005 and 2007. The CCR efficiency value is 1, and the SE-DEA efficiency values are 1.101, 1.024, 1.034 and 1.006, respectively. Therefore, the average SE-DEA efficiency value is completely improved.

In the VRS angle, the SE-DEA efficiency values in Xinjiang, Sichuan and Shanxi are relatively high at 1.030, 1.023 and 1.018, respectively. After the BCC-DEA in these regions becomes valid, further analysis is conducted using the SE-DEA, which evaluates the carbon emission efficiency in various provinces accurately.

\section{SEBM-DEA efficiency evaluation}

The SEBM model integrates the advantages of the SE-DEA model and the EBM model and further compares and analyzes the DMUs.

As shown in Tables 2 and 3 and Figures 1 and 2, in the CRS angle, the average SEBM efficiency values in Shanxi, Inner Mongolia, Sichuan and Xinjiang in 20042014 increase compared with the EBM efficiency values because the DEA in the five provinces in 2004-2014 is valid in some years. Therefore, the SEBM further analyses the years in which the leading line for production is reached. For example, the DEA of Shanxi in 2004, 2005, 2006 and 2007 is valid, and the EBM efficiency value is 1. The SEBM further measures these four years, and the SEBM efficiency values are 1.003, $1.003,1.001$ and 1.001, respectively. Therefore, the average SEBM efficiency value is improved overall. Compared with the SE-DEA and SEBM efficiency values in the four years, the SEBM efficiency value is lower than the SE-DEA efficiency value, and the differences in the four years are lessened. The SEBM model is not only able to further evaluate valid DMUs but also reduce the problem on extreme values, lessen the differences among efficiency values, and ensure that the measurement results meet the actual economic conditions.

In the VRS angle, the SEBM efficiency values in 12 provinces increases compared with the EBM efficiency value. The SEBM-DEA efficiency value in Sichuan and Ningxia is 1, but the SEBM efficiency value in Sichuan decreases compared with SEDEA efficiency value. The SEBM efficiency value in Ningxia increases compared with the SE-DEA efficiency value in Sichuan. This result shows that the SEBM efficiency value lessens the differences in the efficiency values in various regions.

\section{Analysis on time dimension}

To analyze the results on a large scale, we divide the 29 regions into three categories: eastern, central and western. We utilize the CCR, BCC, SE-EBM and SEBM models to analyze the differences in carbon emission efficiency in the three areas and the whole country from 2004 to 2014. The results are reported in Tables 4 and 5. The time trends 


$$
-1121-
$$

of the calculated results in these three areas and the whole country from 2004 to 2014 are reported in Figures 3 and 4.

Table 4. Carbon emission efficiency in China's areas: constant returns to scale

\begin{tabular}{|c|c|c|c|c|c|c|c|c|}
\hline \multirow[b]{2}{*}{ Year } & \multicolumn{4}{|c|}{ CCR-DEA model } & \multicolumn{4}{|c|}{ EBM-DEA model } \\
\hline & $\begin{array}{l}\text { Central } \\
\text { regions }\end{array}$ & $\begin{array}{l}\text { Eastern } \\
\text { regions }\end{array}$ & $\begin{array}{l}\text { West } \\
\text { regions }\end{array}$ & $\begin{array}{l}\text { The whole } \\
\text { country }\end{array}$ & $\begin{array}{l}\text { Central } \\
\text { regions }\end{array}$ & $\begin{array}{l}\text { Eastern } \\
\text { regions }\end{array}$ & $\begin{array}{l}\text { West } \\
\text { regions }\end{array}$ & $\begin{array}{c}\text { The whole } \\
\text { country }\end{array}$ \\
\hline 2006 & 0.541 & 0.423 & 0.692 & 0.548 & 0.687 & 0.609 & 0.816 & 0.702 \\
\hline 2007 & 0.551 & 0.432 & 0.685 & 0.552 & 0.683 & 0.595 & 0.814 & 0.695 \\
\hline 2008 & 0.539 & 0.436 & 0.687 & 0.551 & 0.666 & 0.597 & 0.816 & 0.692 \\
\hline 2009 & 0.523 & 0.421 & 0.671 & 0.535 & 0.645 & 0.584 & 0.786 & 0.670 \\
\hline 2010 & 0.512 & 0.444 & 0.678 & 0.544 & 0.625 & 0.594 & 0.777 & 0.666 \\
\hline 2011 & 0.497 & 0.426 & 0.678 & 0.532 & 0.609 & 0.583 & 0.772 & 0.655 \\
\hline 2012 & 0.475 & 0.411 & 0.656 & 0.513 & 0.595 & 0.581 & 0.754 & 0.645 \\
\hline 2013 & 0.410 & 0.363 & 0.579 & 0.450 & 0.527 & 0.557 & 0.692 & 0.595 \\
\hline 2014 & 0.393 & 0.345 & 0.571 & 0.436 & 0.537 & 0.550 & 0.679 & 0.591 \\
\hline \multirow[b]{2}{*}{ Year } & \multicolumn{4}{|c|}{ SE-DEA model } & \multicolumn{4}{|c|}{ SEBM-DEA model } \\
\hline & $\begin{array}{l}\text { Central } \\
\text { regions }\end{array}$ & $\begin{array}{l}\text { Eastern } \\
\text { regions }\end{array}$ & $\begin{array}{c}\text { West } \\
\text { regions }\end{array}$ & $\begin{array}{l}\text { The whole } \\
\text { country }\end{array}$ & $\begin{array}{l}\text { Central } \\
\text { regions }\end{array}$ & $\begin{array}{l}\text { Eastern } \\
\text { regions }\end{array}$ & $\begin{array}{c}\text { West } \\
\text { regions }\end{array}$ & $\begin{array}{c}\text { The whole } \\
\text { country }\end{array}$ \\
\hline 2004 & 0.544 & 0.405 & 0.664 & 0.533 & 0.701 & 0.610 & 0.817 & 0.706 \\
\hline 2005 & 0.540 & 0.414 & 0.689 & 0.544 & 0.689 & 0.619 & 0.820 & 0.708 \\
\hline 2006 & 0.545 & 0.423 & 0.700 & 0.552 & 0.687 & 0.609 & 0.817 & 0.702 \\
\hline 2007 & 0.552 & 0.432 & 0.685 & 0.552 & 0.683 & 0.595 & 0.814 & 0.695 \\
\hline 2008 & 0.539 & 0.436 & 0.693 & 0.553 & 0.666 & 0.597 & 0.816 & 0.692 \\
\hline 2009 & 0.523 & 0.421 & 0.671 & 0.535 & 0.645 & 0.584 & 0.786 & 0.670 \\
\hline 2010 & 0.512 & 0.444 & 0.679 & 0.544 & 0.625 & 0.594 & 0.777 & 0.666 \\
\hline 2011 & 0.497 & 0.426 & 0.689 & 0.536 & 0.609 & 0.583 & 0.772 & 0.655 \\
\hline 2012 & 0.475 & 0.411 & 0.656 & 0.513 & 0.595 & 0.581 & 0.755 & 0.645 \\
\hline 2013 & 0.410 & 0.363 & 0.582 & 0.451 & 0.527 & 0.557 & 0.692 & 0.595 \\
\hline 2014 & 0.393 & 0.345 & 0.572 & 0.436 & 0.537 & 0.550 & 0.680 & 0.591 \\
\hline
\end{tabular}

Table 5. Carbon emission efficiency in China's areas: variable return scale

\begin{tabular}{c|c|c|c|c|c|c|c|c}
\hline \multirow{2}{*}{ Year } & \multicolumn{5}{|c|}{ BCC-DEA model } & \multicolumn{4}{c}{ EBM-DEA model } \\
\cline { 2 - 9 } & $\begin{array}{c}\text { Central } \\
\text { regions }\end{array}$ & $\begin{array}{c}\text { Eastern } \\
\text { regions }\end{array}$ & $\begin{array}{c}\text { West } \\
\text { regions }\end{array}$ & $\begin{array}{c}\text { The whole } \\
\text { country }\end{array}$ & $\begin{array}{c}\text { Central } \\
\text { regions }\end{array}$ & $\begin{array}{c}\text { Eastern } \\
\text { regions }\end{array}$ & $\begin{array}{c}\text { West } \\
\text { regions }\end{array}$ & $\begin{array}{c}\text { The whole } \\
\text { country }\end{array}$ \\
\hline 2004 & 0.551 & 0.547 & 0.714 & 0.605 & 0.779 & 0.752 & 0.853 & 0.794 \\
2005 & 0.565 & 0.573 & 0.716 & 0.620 & 0.776 & 0.760 & 0.867 & 0.801 \\
2006 & 0.575 & 0.588 & 0.725 & 0.632 & 0.783 & 0.765 & 0.869 & 0.806 \\
2007 & 0.587 & 0.595 & 0.726 & 0.638 & 0.787 & 0.766 & 0.877 & 0.810 \\
2008 & 0.578 & 0.586 & 0.728 & 0.633 & 0.789 & 0.772 & 0.880 & 0.814 \\
2009 & 0.569 & 0.575 & 0.713 & 0.621 & 0.780 & 0.766 & 0.862 & 0.803 \\
2010 & 0.579 & 0.587 & 0.717 & 0.630 & 0.777 & 0.780 & 0.863 & 0.808 \\
2011 & 0.587 & 0.577 & 0.723 & 0.630 & 0.777 & 0.783 & 0.874 & 0.813 \\
2012 & 0.575 & 0.565 & 0.717 & 0.620 & 0.783 & 0.790 & 0.866 & 0.814 \\
2013 & 0.497 & 0.524 & 0.643 & 0.558 & 0.699 & 0.750 & 0.808 & 0.756 \\
2014 & 0.493 & 0.519 & 0.647 & 0.556 & 0.709 & 0.751 & 0.786 & 0.752 \\
\hline
\end{tabular}




\begin{tabular}{c|c|c|c|c|c|c|c|c}
\hline \multirow{2}{*}{ Year } & \multicolumn{5}{|c|}{ SE-DEA model } & \multicolumn{4}{c}{ SEBM-DEA model } \\
\cline { 2 - 9 } & $\begin{array}{c}\text { Central } \\
\text { regions }\end{array}$ & $\begin{array}{c}\text { Eastern } \\
\text { regions }\end{array}$ & $\begin{array}{c}\text { West } \\
\text { regions }\end{array}$ & $\begin{array}{c}\text { The whole } \\
\text { country }\end{array}$ & $\begin{array}{c}\text { Central } \\
\text { regions }\end{array}$ & $\begin{array}{c}\text { Eastern } \\
\text { regions }\end{array}$ & $\begin{array}{c}\text { West } \\
\text { regions }\end{array}$ & $\begin{array}{c}\text { The whole } \\
\text { country }\end{array}$ \\
\hline 2004 & 0.564 & 0.572 & 0.817 & 0.654 & 0.780 & 0.754 & 0.870 & 0.801 \\
2005 & 0.568 & 0.573 & 0.730 & 0.626 & 0.776 & 0.764 & 0.869 & 0.803 \\
2006 & 0.582 & 0.588 & 0.735 & 0.637 & 0.784 & 0.765 & 0.870 & 0.806 \\
2007 & 0.597 & 0.602 & 0.727 & 0.644 & 0.788 & 0.767 & 0.877 & 0.811 \\
2008 & 0.578 & 0.587 & 0.736 & 0.636 & 0.789 & 0.772 & 0.882 & 0.814 \\
2009 & 0.569 & 0.575 & 0.713 & 0.621 & 0.780 & 0.766 & 0.862 & 0.803 \\
2010 & 0.579 & 0.591 & 0.723 & 0.633 & 0.777 & 0.781 & 0.864 & 0.809 \\
2011 & 0.590 & 0.583 & 0.742 & 0.639 & 0.778 & 0.783 & 0.877 & 0.814 \\
2012 & 0.578 & 0.574 & 0.723 & 0.627 & 0.783 & 0.791 & 0.867 & 0.815 \\
2013 & 0.497 & 0.525 & 0.646 & 0.559 & 0.699 & 0.750 & 0.809 & 0.756 \\
2014 & 0.498 & 0.522 & 0.653 & 0.560 & 0.709 & 0.752 & 0.789 & 0.753 \\
\hline
\end{tabular}

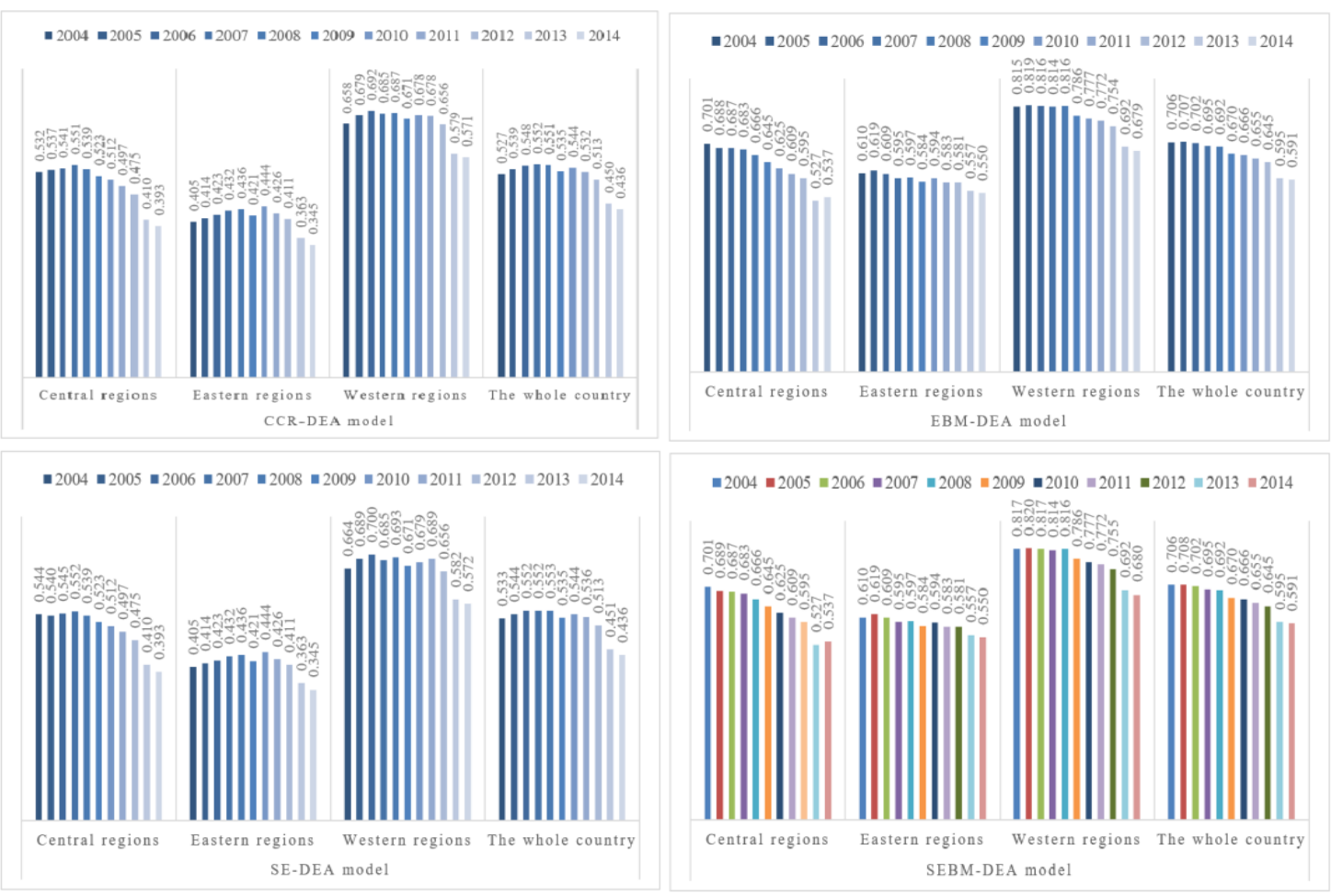

Figure 3. Time dimension analysis of carbon emissions efficiency in China from 2004 to 2014: constant returns to scale

\section{CCR-DEA/BCC-DEA efficiency evaluation}

As shown in Tables 4 and 5 and Figures 3 and 4, In the CRS angle, the nationwide carbon emission efficiency value is low at 0.4-0.56. The trends increased, decreased, and then reached a peak of 0.552 in 2007 . These trends tend to decrease in an increscent range in 2013. The carbon emission efficiency values are high in the west at above 0.57 and reached its peak in 2006 at 0.692 . Then, the values tend to fluctuate and decrease. In the middle area, the efficiency values are $0.4-0.56$ and reach its peak at 0.551 in 
2007. These values decrease continuously and reach 0.393 in 2014 . The efficiency values in the east are the lowest at $0.35-0.45$. These values tend to increase and then decrease, reaching a peak at 0.444 in 2010 , finally decreasing continuously.

In the VRS angle, the nationwide efficiency value is $0.55-0.64$, which is lower than the CCR efficiency value, but still tends to fluctuate and decrease. The value reached its peak at 0.638 in 2007, decreases continuously, and then decreases in an increscent range in 2013. The efficiency value in the west is high at $0.6-0.73$. It tended to fluctuate and decrease, and then increase steadily from 2004 to 2008. It started to decrease in 2009 and decreased in an increscent range in 2013. The east follows with an efficiency value of 0.5-0.6, which fluctuated to decrease and then reached its peak at 0.587 in 2007. The efficiency value in the middle area is relatively low but is not much different from that in the east. The value reached its peak at 0.587 in 2011 and decreased in an increscent range in 2013.

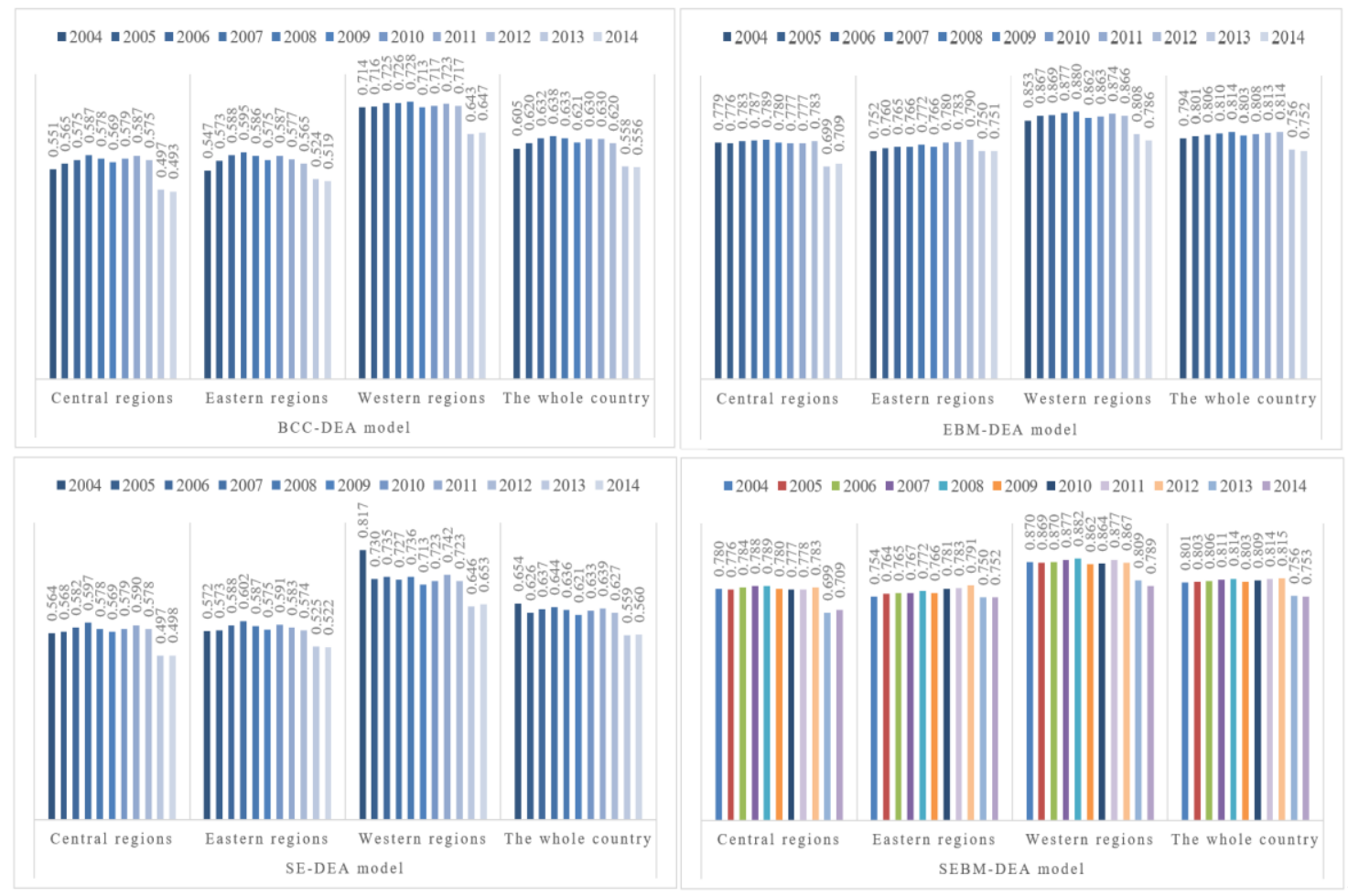

Figure 4. Time dimension analysis of carbon emissions efficiency in China from 2004 to 2014: variable return scale

\section{EBM-DEA efficiency evaluation}

In the CRS angle, EBM-DEA efficiency values in the east, middle, west and nationwide increase compared with the CCR-DEA efficiency value and tend to decrease steadily. The efficiency value is the highest in the west, followed by the middle, and the lowest in the east. This finding clearly shows that the difference in efficiency values in the east, middle and west gradually decreases and that EBM-DEA can decrease the difference in efficiency values in various regions and years.

The EBM-DEA efficiency value with the VRS angle is higher than the EBM-DEA efficiency value with the CRS angle. In the VRS angle, the difference in EBM-DEA 
efficiency values in the east, middle, west and nationwide gradually decreases, and the efficiency values from 2004 to 2012 tended to increase steadily. As shown in Tables 4 and 5 and Figures 3 and 4, the efficiency value is highest in the west (0.77-0.88), followed by the middle (0.7-0.79), and the lowest $(0.75-0.79)$ in the east. In sum, under the VRS angle, the carbon emission efficiency values in the east, middle, west and even nationwide are relatively balanced from 2004 to 2014.

\section{SE-DEA efficiency evaluation}

In the CRS angle, the SE-DEA efficiency value in the middle, west and nationwide increases compared with CCR-DEA efficiency value because the partial CCR-DEA efficiency value of some provinces in some years is 1 and the DEA is valid. The SEDEA model further analyses valid DMUs. As shown in Tables 4 and 5 and Figures 3 and 4, for example, the SE-DEA efficiency value in the middle area in 2004, 2005, 2006 and 2007 was higher than the CCR-DEA efficiency value. The reason for this finding is that the DEA of Shanxi in the middle in 2004, 2005, 2006 and 2007 is valid, and the SE-DEA efficiency values are 1.101, 1.024, 1.034 and 1.006, respectively. Therefore, the average SE-DEA efficiency value in the middle from 2004 to 2007 was higher than the CCR-DEA efficiency value. The carbon emission efficiency value in the middle, east, west and nationwide tends to fluctuate and then decrease. The efficiency value in the west fluctuates greatly, and the carbon emission efficiency value nationwide barely fluctuates.

In the VRS angle, the SE-DEA efficiency values in the east, middle, west and nationwide increase compared with that of the BCC-DEA model. The peak efficiency value in the west appeared in 2004, thus indicating that the SE-DEA further evaluates the DMUs reaching the leading line for production.

\section{SEBM-DEA efficiency evaluation}

In the CRS angle, the SEBM-DEA efficiency values in the middle, east, and west and nationwide increase compared with the EBM-DEA efficiency values and tend to decrease year by year. The efficiency value in the west is the highest. Compared with that in the SE-DEA model, the difference in efficiency values in the west, middle and east decrease, and the difference in different regions and years decreases, as well.

In the VRS angle, the efficiency values in the middle, east, west and even nationwide decrease progressively and increase to different extents compared with EBM-DEA efficiency values. With respect to the SE-DEA model, the difference in different regions and years gradually decreases. This finding shows that the SEBM-DEA model integrates the characteristics of EBM-DEA and SE-DEA to evaluate the efficiency value of DMUs more completely than the other models.

\section{Conclusion}

First, this study thoroughly analyses the development of a theoretical model for carbon emission efficiency and finds that traditional DEA models, namely, CCR-DEA, BCC-DEA, SE-DEA and EBM-DEA, have some inadequacies. For the CCR/BCC model, the application restriction of efficient boundary is not considered. The problem of factor proportion change synchronization (non-realistic) also exists. The SBM/EBM model is unsuitable for a data cube with more valid cells. The SE-DEA model is 
unsuitable for a condition in which the factors of leading surface are not changeable in the same proportion. Therefore, this study proposes the SEBM model, which can effectively solve the above-mentioned problems and contribute to carbon emission efficiency theory using data analysis in China.

Second, we analyze and calculate the carbon emission efficiency in 29 regions of China in 2004-2014 using five models: CCR-DEA, BCC-DEA, SE-DEA, EBM-DEA and SEBM-DEA. The analysis result in spatial dimension shows that China has the highest carbon emission efficiency in the west, average in the middle, and the lowest in the east. Under the CRS angle (in five models), Hebei and Liaoning rank high in the east, Shanxi ranks high in the middle and Xinjiang and Ningxia rank high in the west. Under the VRS angle (in five models), Hebei and Shandong have the highest efficiency in the east, Shanxi has the highest in the middle and Sichuan and Xinjiang are the highest in the west. The analysis result in the time dimension shows that in the CRS and VRS angles, the west has the highest efficiency, followed by the middle, and the east has the lowest. Conversely, in the CRS angle, the east and the west have a huge difference in efficiency. Since 2006, China's carbon emission efficiency values have generally increased, thus indicating that the policy of energy saving and emission reduction is effective in China.

Finally, based on the efficiency values in various regions in China, the environment has been damaged to an extreme degree, carbon emission is too high, carbon emission efficiency is the lowest in the country, and the energy utilization rate is low in the east. These results likely stem from the extensive development of the economy in recent years. Although the economy in the east is developing rapidly, the industrial sector will be further transformed to reduce carbon emission. In the middle regions, development is fast, but with the unreasonable output-input matching, the economic aggregate cannot be guaranteed to expand rapidly, and the carbon emission efficiency cannot be guaranteed to be low. Clearly, the middle regions follow behind the east in terms of economic development. The extensive economy of the west cannot continue while it is developing on a large scale. Moreover, the west should realize that its geographic position is not good and that it should pay more attention to the development of new energy and high value-added economy to develop its economy.

Acknowledgements. This paper was supported by the 2017 Henan water resources safety and clean energy collaborative management innovative technology team and the National Natural Science Foundation of China (71573086).

\section{REFERENCES}

[1] Adland, R., Alger, H., Banyte, J., Jia, H. (2017): Does fuel efficiency pay? Empirical evidence from the drybulk timecharter market revisited. - Transportation Research Part A: Policy and Practice 95: 1-12.

[2] Andersen, P., Petersen, N. C. (1993): A procedure for ranking efficient units in data envelopment analysis. - Management Science 39(10): 1261-1264.

[3] Andrieș, A. M., Ursu, S. G. (2016): Financial crisis and bank efficiency: An empirical study of European banks. - Economic Research-Ekonomska Istraživanja 29(1): 485-497.

[4] Ang, B. W. (1999): Is the energy intensity a less useful indicator than the carbon factor in the study of climate change. - Energy Policy 27(5): 943-946. 
[5] Baležentis, T., Li, T., Streimikiene, D., Baležentis, A. (2016): Is the Lithuanian economy approaching the goals of sustainable energy and climate change mitigation? Evidence from DEA-based environmental performance index. - Journal of Cleaner Production 116: 23-31.

[6] Banker, R. D., Charnes, A., Cooper, W. W. (1984): Some models for estimating technical and scale inefficiencies in data envelopment analysis. - Management Science 30(9): 1078-1092.

[7] Bretschger, L., Valente, S. (2016): Productivity gaps and tax policies under asymmetric trade. - Economics Working Paper Series 239: 1-37. DOI: 10.3929/ethz-a-010611130.

[8] Charnes, A., Cooper, W. W., Rhodes, E. (1978): Measuring the efficiency of decision making units. - European Journal of Operational Research 2(6): 429-444.

[9] Cranmer, S. R. (2016): Predictions for dusty mass loss from asteroids during close encounters with solar probe plus. - Earth, Moon, and Planets 118(2-3): 51-79.

[10] Dzonzi-Undi, J., Li, S. (2016): RETRACTED: Safety and environmental inputs investment effect analysis: Empirical study of selected coal mining firms in China. Resources Policy 47: 178-186.

[11] Grinsven, H. V., Tiktak, A., Rougoor, C. W. (2016): Evaluation of the Dutch implementation of the nitrates directive, the water framework directive and the national emission ceilings directive. - Njas Wageningen Journal of Life Sciences 78: 69-84.

[12] Henson, S. A., Yool, A., Sanders, R. (2015): Variability in efficiency of particulate organic carbon export: A model study. - Global Biogeochemical Cycles 29(1): 33-45.

[13] Kaya, Y., Yokobori, K. (1993): Global Environment, Energy, and Economic Development. - United Nations University. Tokyo.

[14] Kim, J. (2016): Vehicle fuel-efficiency choices, emission externalities, and urban sprawl. - Economics of Transportation 5: 24-36.

[15] Liu, L., Ma, X. Q., Mao, Z. J. (2014): Empirical study on the economic effect of energy conservation and emission reduction in different industrial stages. - Advanced Materials Research 962: 1541-1546.

[16] Marklund, P. O., Samakovlis, E. (2007): What is driving the EU burden-sharing agreement: Efficiency or equity? - Journal of Environmental Management 85(2): 317329.

[17] Mielnik, O., Goldemberg, J. (1999): The evolution of the "Carbonization Index" in developing countries. - Energy Policy 27(05): 307-308.

[18] National Bureau of Statistics of the People's Republic of China (2015): China Statistical Yearbooks 2015. - NBS, Beijing.

[19] Niu, S., Jia, Y., Ye, L., Dai, R., Li, N. (2016): Does electricity consumption improve residential living status in less developed regions? An empirical analysis using the quantile regression approach. - Energy 95: 550-560.

[20] Obeng, K., Sakano, R., Naanwaab, C. (2016): Understanding overall output efficiency in public transit systems: The roles of input regulations, perceived budget and input subsidies. - Transportation Research Part E: Logistics and Transportation Review 89: 133-150.

[21] Ramanathan, R. (2002): Combining Indicators of Energy Consumption and $\mathrm{CO}_{2}$ Emissions: Across-country Comparison. - International Journal of Global Energy Issues 17(03): 214-227.

[22] Ramanathan, R. (2005): An analysis of energy consumption and carbon dioxide emissions in countries of the Middle East and North Africa. - Energy 30(15): 2831-2842.

[23] Ramanathan, R. (2006): A multi-factor efficiency perspective to the relationships among world GDP, energy consumption and carbon dioxide emissions. - Technological Forecasting \& Social Change 73(5): 483-494.

[24] Roar, A., Harrison, A., Justina, B., Hai, Y. J. (2017): Does fuel efficiency pay? Empirical evidence from the drybulk timecharter market revisited. - Transportation Research Part A: Policy and Practice 95: 1-12. 
[25] Sarkar, S. (2013): Testing weak form efficiency of indian stock market - an empirical study on BSE. - IEEE Transactions on Antennas \& Propagation 18(1): 112-114.

[26] Shao, Y., Wang, S. (2016): Productivity growth and environmental efficiency of the nonferrous metals industry: An empirical study of China. - Journal of Cleaner Production 137: $1663-1671$.

[27] Sun, J. W. (2005): The decrease of $\mathrm{CO}_{2}$ emission intensity is decarbonization at national and global levels. - Energy Policy 33(8): 975-978.

[28] Szczepańska, K., Wiśniewska, M. (2012): Human performance improvement in the health care organizations. Results of empirical study in Poland. - Foundations of Management 4(2): 97-108.

[29] Tavana, M., Mirzagoltabar, H., Mirhedayatian, S. M., Saen, R. F., Azadi, M. (2013): A new network epsilon-based DEA model for supply chain performance evaluation. Computers \& Industrial Engineering 66(2): 501-513.

[30] Tone, K., Tsutsui, M. (2010): An epsilon-based measure of efficiency in DEA-A third pole of technical efficiency. - European Journal of Operational Research 207(3): 15541563.

[31] Vaidya, K., Campbell, J. (2016): Multidisciplinary approach to defining public eprocurement and evaluating its impact on procurement efficiency. - Information Systems Frontiers 18(2): 333-348.

[32] Van Grinsven, H. J., Tiktak, A., Rougoor, C. W. (2016): Evaluation of the Dutch implementation of the nitrates directive, the water framework directive and the national emission ceilings directive. - NJAS-Wageningen Journal of Life Sciences 78: 69-84.

[33] Wang, J. T., Cao, Q. F., Chen, T. Y., Wang, X. (2016): An empirical study on the technical efficiency of foreign direct investment in China with environmental constraints. - The Chinese Economy 49(2): 94-104.

[34] Wang, Q., Zhou, P., Zhou, D. (2012): Efficiency measurement with carbon dioxide emissions: the case of China. - Applied Energy 90(1): 161-166.

[35] Wang, Q. W., Zhou, P., Shen, N., Wang, S. S. (2013): Measuring carbon dioxide emission performance in Chinese provinces: a parametric approach. - Renewable and Sustainable Energy Reviews 21: 324-330.

[36] Wang, S., Fang, C., Wang, Y., Huang, Y., Ma, H. (2015): Quantifying the relationship between urban development intensity and carbon dioxide emissions using a panel data analysis. - Ecological Indicators 49: 121-131.

[37] Wang, S., Zhou, C., Li, G., Feng, K. (2016): $\mathrm{CO}_{2}$, economic growth, and energy consumption in China's provinces: Investigating the spatiotemporal and econometric characteristics of China's $\mathrm{CO}_{2}$ emissions. - Ecological Indicators 69: 184-195.

[38] Xian, Y., Huang, Z. (2016): Sources of carbon productivity change: A decomposition and disaggregation analysis based on global Luenberger productivity indicator and endogenous directional distance function. - Ecological Indicators 66: 545-555.

[39] Xu, S., Zhang, Z., Si, D. (2014): The study of the operating performance of marine industry in the blue economic zone: An empirical analysis based on DEA and Tobit Model. - Asian Agricultural Research 6(6): 16-21.

[40] Yun, L., Dan, N., Xin, G. Z., Yan, B. L. (2017): Market structure and performance: An empirical study of the Chinese solar cell industry. - Renewable and Sustainable Energy Reviews 70: 78-82.

[41] Zaim, O., Taskin, F. (2000): Environmental efficiency in carbon dioxide emissions in the OECD: A non-parametric approach. - Journal of Environmental Management 58(2): 95107.

[42] Zhang, Z., Qu, J. S., Zeng, J. J. (2008): A quantitative comparison and analysis on the assessment indicators of greenhouse gases emission. - Journal of Geographical Sciences 18(04): 387-399.

[43] Zhou, P., Ang, B. W., Poh, K. L. (2006): Slacks-based efficiency measures for modeling environmental performance. - Ecological Economics 60(1): 111-118. 
[44] Zhou, P., Ang, B. W., Han, J. Y. (2010): Total factor carbon emission performance: a Malmquist index analysis. - Energy Economics 32(1): 194-201.

[45] Zhou, Y., Li, Y. P., Huang, G. H. (2015): Planning sustainable electric-power system with carbon emission abatement through CDM under uncertainty. - Applied Energy 140: 350-364. 